\title{
Mutual Influence of Special Components in Baotou Steel Blast Furnace Slag on the Crystallization Behavior of Glass
}

\author{
Yici Wang, ${ }^{1,2}$ Qi Jiang, ${ }^{2}$ Guoping Luo, ${ }^{1,2}$ Wenwu Yu, ${ }^{2}$ and Yan Ban ${ }^{2}$ \\ ${ }^{1}$ College of Metallurgical and Ecological Engineering, University of Science and Technology Beijing, Beijing 100083, China \\ ${ }^{2}$ College of Material and Metallurgy, Inner Mongolia University of Science and Technology, Baotou 014010, China
}

Correspondence should be addressed to Yici Wang, wangyici01060@163.com

Received 18 June 2012; Revised 7 September 2012; Accepted 10 September 2012

Academic Editor: Shien-Ping Feng

Copyright ( 2012 Yici Wang et al. This is an open access article distributed under the Creative Commons Attribution License, which permits unrestricted use, distribution, and reproduction in any medium, provided the original work is properly cited.

\begin{abstract}
In the process of glass-ceramics prepared with Baotou steel blast furnace slag, quartz sand, and other raw materials by melting method, the mutual influence of the special components such as $\mathrm{CaF}_{2}, \mathrm{RE}_{X} \mathrm{O}_{Y}, \mathrm{TiO}_{2}, \mathrm{~K}_{2} \mathrm{O}$, and $\mathrm{Na}_{2} \mathrm{O}$ in the blast furnace slag on the crystallization behavior of parent glass was investigated using differential thermal analysis (DTA) and X-ray diffraction (XRD). The results show that the special components in slag can reduce the crystallization temperature and promote crystallization of glass phase, which belongs to surface crystallization of glass, and they cannot play the role of the nucleating agent; the major crystal phase composed of diopside, diopside containing aluminum and anorthite, is slightly different from the expected main crystal phase of diopside. Therefore, the nucleating agents of proper species and quantity must be added into the raw materials in order to obtain glass-ceramics. The results have important theoretical guidance meaning for realizing industrial production of Baotou steel blast furnace slag glass-ceramics preparation.
\end{abstract}

\section{Introduction}

Glass-ceramics are uniform polycrystalline materials with glasses and crystals, which are processed and formed as glasses and then converted into a crystalline ceramic by a subsequent heat treatment $[1,2]$. It is of great significance to prepare glass-ceramics from blast furnace slag for improving utilization and added value of iron smelting slag, recovering heat of slag, increasing economic benefit of enterprises, and reducing environmental pollution [3-10]. Baotou steel blast furnace slag is unique in the world because it contains some special components such as $\mathrm{CaF}_{2}, \mathrm{RE}_{X} \mathrm{O}_{Y}, \mathrm{TiO}_{2}, \mathrm{~K}_{2} \mathrm{O}, \mathrm{Na}_{2} \mathrm{O}$, and the radioactive element thorium [11]. Among them, $\mathrm{CaF}_{2}$ and $\mathrm{TiO}_{2}$ can act as nucleating agent to promote crystallization of glass [12-14], and $\mathrm{K}_{2} \mathrm{O}$ and $\mathrm{Na}_{2} \mathrm{O}$ can decrease the melting point of glass, but there are few reports so far regarding the effect of $\mathrm{RE}_{X} \mathrm{O}_{Y}, \mathrm{Nb}_{2} \mathrm{O}_{5}$, and $\mathrm{ThO}_{2}$ on the crystallization behavior of glass in the process of glassceramics prepared. These special components make the crystallization behavior of glass-ceramics prepared from blast furnace slag become more complex, and the related theory of glass-ceramics prepared from ordinary blast furnace slag is not completely applicable to Baotou steel blast furnace slag. Therefore, the mutual influence of the special components in Baotou steel blast furnace slag on the crystallization behavior of parent glass was investigated without any nucleating agents added in this paper. The results not only are a supplement to the theory of slag glass-ceramics preparation, but also had theoretical guidance meaning and practical reference value for realizing industrial production of Baotou steel blast furnace slag glass-ceramics preparation.

\section{The Chemical Composition Design of the Parent Glass}

Two problems must be taken into account in chemical composition design of the parent glass: the structural stability of the parent glass and the major crystal phases after glass crystallization. Various crystal phases can be obtained due to different silicon-oxygen ratio $(\mathrm{Si} / \mathrm{O})$ from the viewpoint of crystal chemistry, and the prepared glassceramics should have higher mechanical strength, good wear resistance, chemical stability, and thermal stability. 
TABLE 1: Chemical composition of the parent glass (wt\%).

\begin{tabular}{lccc}
\hline $\mathrm{CaO}$ & $\mathrm{SiO}_{2}$ & $\mathrm{Al}_{2} \mathrm{O}_{3}$ & $\mathrm{MgO}$ \\
\hline 26 & 54 & 10 & 10 \\
\hline
\end{tabular}

TABle 2: The chemical composition of Baotou steel blast furnace slag $(\mathrm{wt} \%)$.

\begin{tabular}{|c|c|}
\hline Components & Mass percentage \\
\hline $\mathrm{TFe}$ & 1.20 \\
\hline $\mathrm{FeO}$ & 1.20 \\
\hline $\mathrm{SiO}_{2}$ & 35.94 \\
\hline $\mathrm{CaF}_{2}$ & 1.52 \\
\hline $\mathrm{P}$ & - \\
\hline S & 1.06 \\
\hline $\mathrm{K}_{2} \mathrm{O}$ & 0.53 \\
\hline $\mathrm{Na}_{2} \mathrm{O}$ & 1.34 \\
\hline $\mathrm{CaO}$ & 33.37 \\
\hline $\mathrm{MgO}$ & 10.10 \\
\hline $\mathrm{Al}_{2} \mathrm{O}_{3}$ & 12.08 \\
\hline $\mathrm{TiO}_{2}$ & 1.38 \\
\hline $\mathrm{MnO}$ & 0.55 \\
\hline $\mathrm{RE}_{X} \mathrm{O}_{Y}$ & 0.78 \\
\hline $\mathrm{Cu}$ & 0.004 \\
\hline $\mathrm{Zn}$ & 0.002 \\
\hline $\mathrm{C}$ & 0.36 \\
\hline As & - \\
\hline $\mathrm{Pb}$ & - \\
\hline $\mathrm{Bi}$ & 0.0042 \\
\hline Sn & - \\
\hline $\mathrm{Sb}$ & - \\
\hline $\mathrm{Nb}_{2} \mathrm{O}_{5}$ & 0.0092 \\
\hline $\mathrm{ThO}_{2}$ & 0.016 \\
\hline
\end{tabular}

Consequently, according to the $\mathrm{CaO}-\mathrm{Al}_{2} \mathrm{O}_{3}-\mathrm{SiO}_{2}$ ternary system phase diagram [15] (shown in Figure 1), in which the mass percentage of $\mathrm{MgO}$ is $10 \%$, the pyroxenes crystal (diopside $\mathrm{CaMg}\left(\mathrm{SiO}_{3}\right)_{2}$ ) was selected as the major crystal phase and the chemical composition of point A in Figure 1 was determined as that of the parent glass (shown in Table 1). The designed parent glass can get a lower melting temperature because point $\mathrm{A}$ is near the ternary eutectic point.

\section{Experimental Materials, Content, and Method}

3.1. Experimental Materials. Baotou steel blast furnace slag and quartz sand were used as the major raw materials, added with a small amount of pure chemical reagents $\mathrm{CaO}, \mathrm{MgO}$, and $\mathrm{Al}_{2} \mathrm{O}_{3}$, to prepare a mixture according to the chemical composition of the parent glass in Table 1. The chemical composition of Baotou steel blast furnace slag determined by means of chemical analysis is shown in Table 2, and the mass percentage of $\mathrm{SiO}_{2}$ in the quartz sand is $97.15 \%$.

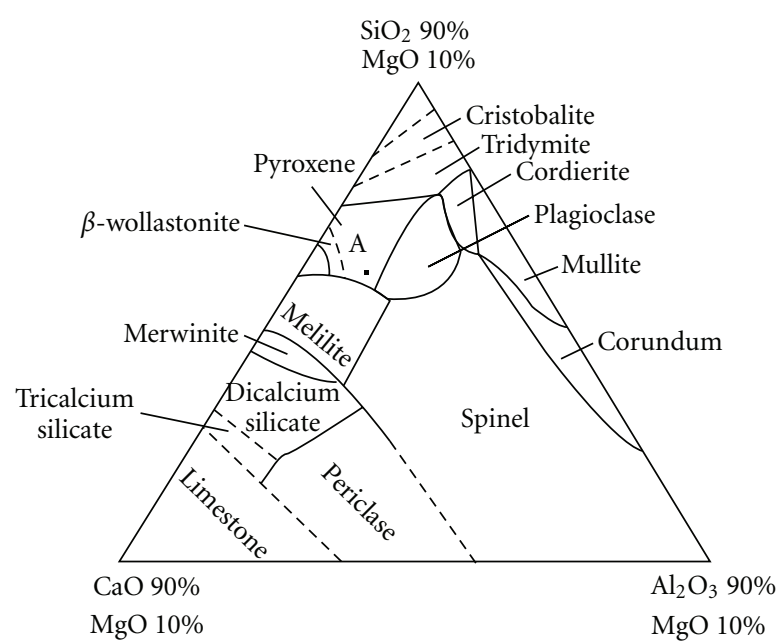

Figure 1: $\mathrm{CaO}-\mathrm{Al}_{2} \mathrm{O}_{3}-\mathrm{SiO}_{2}$ ternary system phase diagram containing $10 \% \mathrm{MgO}$.

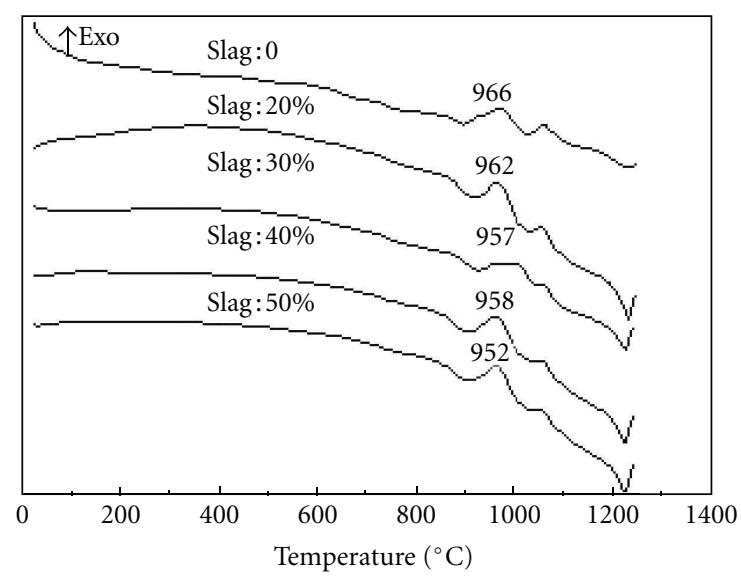

FIgURE 2: The DTA curves for each parent glass.

Besides the major chemical components $\mathrm{CaO}, \mathrm{MgO}$, $\mathrm{SiO}_{2}$, and $\mathrm{Al}_{2} \mathrm{O}_{3}$, there is a small amount of special components such as $\mathrm{CaF}_{2}, \mathrm{RE}_{X} \mathrm{O}_{Y}, \mathrm{~K}_{2} \mathrm{O}, \mathrm{Na}_{2} \mathrm{O}, \mathrm{TiO}_{2}, \mathrm{Nb}_{2} \mathrm{O}_{5}$, and $\mathrm{ThO}_{2}$ in the blast furnace slag, and the total mass percentage of these special components is about $5.58 \%$, among which, $1.52 \% \mathrm{CaF}_{2}, 0.78 \% \mathrm{RE}_{X} \mathrm{O}_{Y}, 0.53 \% \mathrm{~K}_{2} \mathrm{O}$, $1.34 \% \mathrm{Na}_{2} \mathrm{O}, 1.38 \% \mathrm{TiO}_{2}, 0.0092 \% \mathrm{Nb}_{2} \mathrm{O}_{5}$, and $0.016 \%$ $\mathrm{ThO}_{2}$.

3.2. Experimental Content. In our experiment, the $\mathrm{CaO}-$ $\mathrm{MgO}-\mathrm{Al}_{2} \mathrm{O}_{3}-\mathrm{SiO}_{2}$ system glass-ceramics were prepared by melting method. And the change of mass percentage of the special components $(0,1.05 \%, 1.58 \%, 2.11 \%$, and $2.64 \%$ ) was realized by changing the proportion of the blast furnace slag in the parent glass $(0,20 \%, 30 \%, 40 \%$, and $50 \%)$. The mutual influence of such special components as $\mathrm{CaF}_{2}, \mathrm{RE}_{X} \mathrm{O}_{Y}, \mathrm{~K}_{2} \mathrm{O}, \mathrm{Na}_{2} \mathrm{O}$, and $\mathrm{TiO}_{2}$ on the crystallization behavior of the parent glass was studied under the condition of adding no nucleating agents (including nucleation and crystallization temperature of the parent glass, crystal phase 
TABLE 3: Raw materials ratio of the parent glass.

\begin{tabular}{lcccccccc}
\hline Sample & Blast furnace slag $(\mathrm{g})$ & Quartz sand $(\mathrm{g})$ & $\mathrm{CaO}(\mathrm{g})$ & $\mathrm{Al}_{2} \mathrm{O}_{3}(\mathrm{~g})$ & $\mathrm{MgO}(\mathrm{g})$ & $\mathrm{B}_{2} \mathrm{O}_{3}(\mathrm{~g})$ & $\mathrm{Special} \mathrm{components}(\%)^{\mathrm{ThO}}(\%)$ \\
\hline 1 & 0 & 55.58 & 26.53 & 10.15 & 10.20 & 2.04 & 0 & 0 \\
2 & 20 & 47.24 & 19.27 & 7.53 & 7.97 & 2.04 & 1.05 & 0.003 \\
3 & 30 & 43.07 & 15.64 & 6.21 & 6.85 & 2.04 & 1.58 & 0.005 \\
4 & 40 & 38.89 & 12.01 & 4.90 & 5.74 & 2.04 & 2.11 & 0.006 \\
5 & 50 & 34.72 & 8.38 & 3.59 & 4.62 & 2.04 & 2.64 & 0.008 \\
\hline
\end{tabular}

composition, and microstructure). The raw materials ratio of the parent glass was shown in Table 3. In order to decrease the melting temperature of the glass, the pure chemical reagent $\mathrm{B}_{2} \mathrm{O}_{3}(2 \%)$ as flux was added. When the mass percentage of the blast furnace slag was less than $50 \%$ and that of $\mathrm{ThO}_{2}$ in the parent glass was no more than $0.008 \%(80 \mathrm{ppm})$, that is to say, the content of the radioactive element thorium in the prepared glass-ceramics was not excessive.

3.3. Experimental Method. The particle sizes for various materials were ground to smaller than 200 mesh, weighed accurately according to the raw material ratio of the parent glass in Table 3 , and mixed completely. Then, the mixture was put into a corundum crucible and melted in a furnace using Si-Mo rod as heater at $1490^{\circ} \mathrm{C}$ for $4 \mathrm{~h}$. After that, the melt was poured into three steel molds. The moulds with the cooled melts were put into another furnace with its temperature $600^{\circ} \mathrm{C}$ and held for $2 \mathrm{~h}$. After the annealing process, the parent glass prepared from the mixture was obtained.

The mutual influence of the special components in the blast furnace slag on the crystallization behavior of the parent glass was investigated by the method of differential thermal analysis (DTA) and X-ray diffraction (XRD).

The nucleation and crystallization temperatures of the parent glass were determined by an STA 449C comprehensive differential thermal analyzer. Because the nucleation of glass is endothermic, and its crystallization is exothermic, according to Tamman curve [16], the nucleation and crystallization of glass are both in a certain temperature range and, respectively, presented as the endothermic peak and exothermic peak on the DTA curve. Then, the parent glass was heat-treated at the nucleation and crystallization temperatures. XRD was used to identify the crystalline phases present in the glass after heat treatment, and the degree of crystallization, crystal phase composition, and their relative contents in the glass sample can be determined by observing the intensity of X-ray diffraction peaks.

\section{Experimental Results and Analysis}

4.1. The Impact of Special Components on the Nucleation and Crystallization Temperatures of the Parent Glass. The nucleation and crystallization temperatures of the parent glass were determined by the method of differential thermal analysis. The parent glass was ground to smaller than 200 mesh, filled into a corundum pot, then heated up to $1250^{\circ} \mathrm{C}$ at a rate of $10^{\circ} \mathrm{C} / \mathrm{min}$ in argon. The DTA curves for each

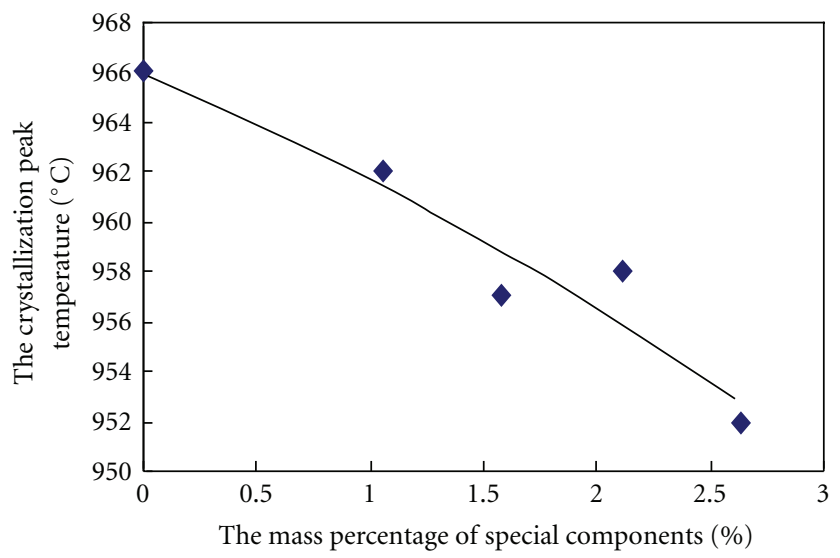

FIgURE 3: The impact of special components in the blast furnace slag on the crystallization temperatures of glass.

parent glass are shown in Figure 2, and the impact of special components in the blast furnace slag on the crystallization temperatures is shown in Figure 3. From Figures 2 and 3, it can be found that there are no obvious endothermic peaks corresponding to the nucleation process of glass, but there exist obvious exothermic peaks corresponding to the crystallization process of glass on the DTA curves for each sample. Due to one exothermic peak corresponding to the crystallization of a kind of mineral, two exothermic peaks on each DTA curve show that there are at least two kinds of minerals to precipitate. The area of the first peak is much larger than that of the second peak, which is caused by the precipitation of the main crystal phase, and the second peak stands for the precipitation of the minor crystalline phase. In this paper, the crystallization temperature of the main crystal phase was used as the crystallization temperature of the parent glass. When the blast furnace slag was not added into the raw materials of parent glass (the mass percentage of the special components was 0 in the parent glass), the crystallization peak temperature was $966^{\circ} \mathrm{C}$; when the ratio of the blast furnace slag was increased to $50 \%$ (the mass percentage of the special components was $2.64 \%$ ), it decreased to $952^{\circ} \mathrm{C}$. Consequently, the crystallization peak temperature of the parent glass was gradually decreased with the increase of the blast furnace slag proportion in the parent glass, that is to say, the special components in the blast furnace could reduce the crystallization temperature of parent glass and promote the crystallization of the glass phase. The more slag addition means the more special components in the slag was added into the raw materials of 


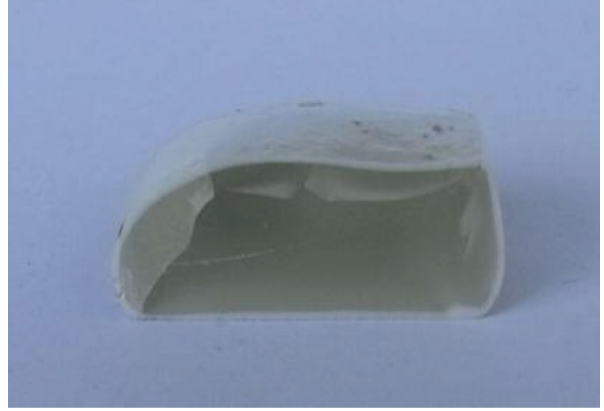

(a) Containing $20 \%$ slag (crystallization time $1 \mathrm{~h}$ )

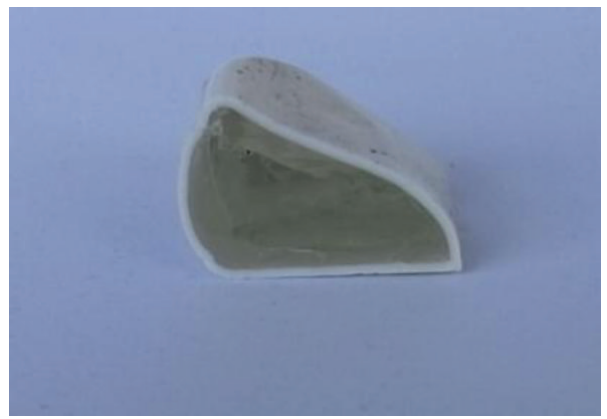

(c) Containing $20 \%$ slag (crystallization time $2 \mathrm{~h}$ )

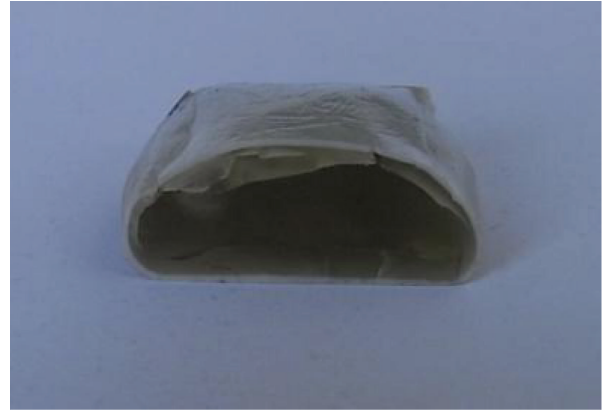

(b) Containing $40 \%$ slag (crystallization time $1 \mathrm{~h}$ )

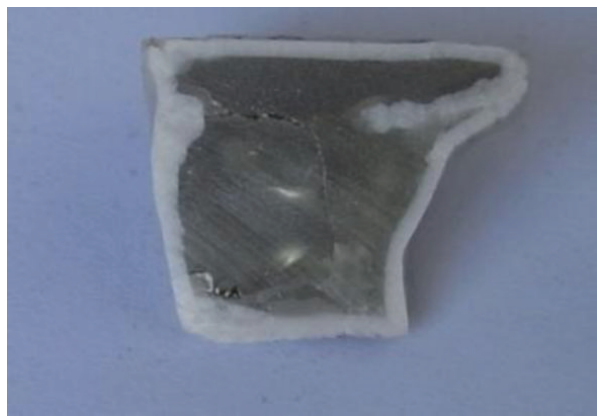

(d) containing $40 \%$ slag (crystallization time $2 \mathrm{~h}$ )

FIGURE 4: The crystallization state of glass samples containing $20 \%$ and $40 \%$ blast furnace slag after heat treatment.

the basic glass, in which, such special components as $\mathrm{CaF}_{2}$ and $\mathrm{TiO}_{2}$ are nucleating agents to promote the crystallization of glass. And the more nucleating agents can promote crystallization of glass. Therefore, it makes the crystallization temperature of glass reduce.

\subsection{The Impact of Special Components on the Crystallization of} the Parent Glass. According to the DTA curves of the parent glass samples, the heat treatment system of glass was selected as nucleation temperature $770^{\circ} \mathrm{C}$, nucleation time 1 hour and crystallization temperature $962^{\circ} \mathrm{C}$, crystallization time 1 hour. The crystallization temperature was selected as $962^{\circ} \mathrm{C}$, because it was the highest for the glass samples, respectively, containing slag 20\%,30\%, 40\%, and 50\%. Consequently, it ensures that crystals can precipitate from all the glass samples at this temperature. The glass samples containing $20 \%$ and $40 \%$ blast furnace slag after heat treatment is shown in Figures 4(a) and 4(b). From Figures 4(a) and 4(b), it can be seen that the surface of the samples is a crystal layer and all the rest part of the samples is glass when no nucleating agents were added into the raw materials of the parent glass. The surface layer has been separated from the inner glass, grinded into powders, and detected by XRD; the XRD results were shown in Figure 5, and three minerals were found. Consequently, the surface layer is crystallized. The crystallization state of glass samples containing $0 \%, 20 \%$, $30 \%, 40 \%$, and $50 \%$ blast furnace slag after heat treatment is similar, which belongs to the surface crystallization. In this paper, the glass samples containing $20 \%$ and $40 \%$ blast furnace slag after heat treatment were selected as the typical representative. With the increase of the blast furnace ratio, the color of the parent glass becomes darker. When the crystallization time was extended to $2 \mathrm{~h}$, the other heat treatment parameters were unchanged, the crystallization state of these two glass samples is shown in Figures 4(c) and 4(d). It can be found that the crystal layer thickness of samples increases with prolonging the crystallization time and/or increasing the blast furnace slag ratio in the parent glass (that is, increasing mass percentage of the special components).

The special components in the blast furnace slag can promote the crystallization of the glass phase, which belongs to surface crystallization of glass, and they cannot play the role of nucleating agents to provide opportunities of nucleation, but the microdefects in the surface of the glass can provide heterogeneous nucleation sites and induce the crystallization during heat treatment. Consequently, the nucleating agents of proper species and quantity must be added into the raw materials in order to obtain uniform and compact grains in the glass body.

\subsection{The Impact of Special Components on the Crystal-} lization Phase after the Parent Glass Heat Treatment. The crystallization phase after the parent glass heat treatment was determined by XRD, and the results are shown in Figure 5. From Figure 5, it can be found that diopside $\mathrm{Ca}(\mathrm{Mg}, \mathrm{Al})(\mathrm{Si}, \mathrm{Al})_{2} \mathrm{O}_{6}$ and anorthite $\mathrm{CaAl}_{2} \mathrm{Si}_{2} \mathrm{O}_{8}$ are the major minerals precipitated from the glass sample containing $20 \%$ blast furnace slag. Diopside containing aluminium $\mathrm{Ca}\left(\mathrm{Mg}_{0.5} \mathrm{Al}_{0.5}\right)\left(\mathrm{Al}_{0.5} \mathrm{Si}_{1.5} \mathrm{O}_{6}\right)$ was also precipitated from the 

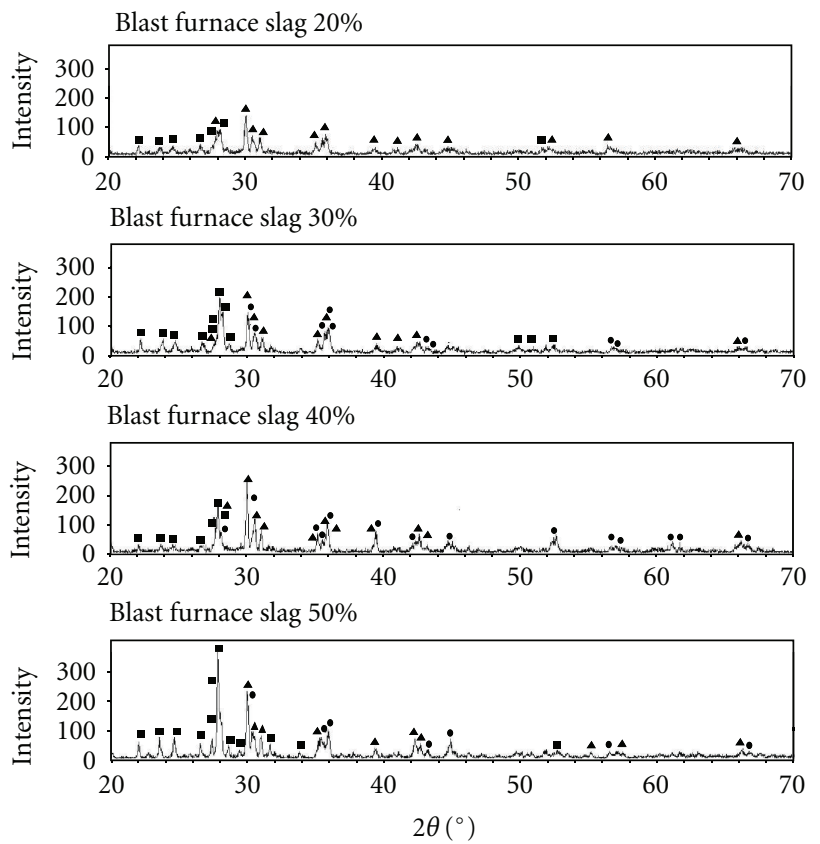

- D Diopside $\mathrm{Ca}(\mathrm{Mg}, \mathrm{Al})(\mathrm{Si}, \mathrm{Al}){ }_{2} \mathrm{O}_{6}$

- - Anorthite $\mathrm{CaAl}_{2} \mathrm{Si}_{2} \mathrm{O}_{8}$

- - Diopside containing aluminium $\mathrm{Ca}\left(\mathrm{Mg}_{0.5} \mathrm{Al}_{0.5}\right)\left(\mathrm{Al}_{0.5} \mathrm{Si}_{1.5} \mathrm{O}_{6}\right)$

FIGURE 5: XRD patterns of the crystallization phase after the parent glass heat-treated.

glass samples containing 30\%, 40\%, and 50\% blast furnace slag except for diopside and anorthite. And the quantity of diopside, anorthite, and diopside containing aluminum increased with the increase of the blast furnace slag content in the parent glass (i.e., the increase of special components). Therefore, the special components in the blast furnace slag can promote crystallization of glass, which is consistent with the DTA results. However, the major minerals precipitated from the parent glass were slightly different from the expectation. In order to get the expected major crystalline phase diopside, the appropriate quantity nucleating agents must be added to promote the precipitation of diopside and inhibit the precipitation of anorthite.

\section{Conclusions}

(1) In the process of glass-ceramics prepared with Baotou steel blast furnace slag by melting method, the special components such as $\mathrm{CaF}_{2}, \mathrm{RE}_{X} \mathrm{O}_{Y}, \mathrm{TiO}_{2}$, $\mathrm{K}_{2} \mathrm{O}$, and $\mathrm{Na}_{2} \mathrm{O}$ in the blast furnace slag can reduce the crystallization temperature of parent glass and promote the crystallization of glass phase.

(2) The special components in the blast furnace slag can promote the crystallization of the glass phase, which belongs to surface crystallization of glass, but they cannot play the role of nucleating agents.

(3) When no nucleating agents were added, the major crystals precipitated from the parent glass are diopside, diopside containing aluminum, and anorthite, which are slightly different from the expectation.

\section{Acknowledgments}

The research work in this paper was financially supported by the Major Project of Inner Mongolia Natural Science Foundation (2011ZD06) and Research Projects of Inner Mongolia Colleges and Universities (NJZZ11141).

\section{References}

[1] H. N. Xiao, W. Q. Peng, and C. M. Deng, "Preparation of microcrystalline ceramic technology, performance, and uses," Chinese Ceramics, vol. 36, pp. 31-33, 2000.

[2] A. A. Francis, "Conversion of blast furnace slag into new glassceramic material," Journal of the European Ceramic Society, vol. 24, no. 9, pp. 2819-2824, 2004.

[3] Z. F. Shan, "Domestic and foreign steel slag processing technology and utilization technology development," Industrial Safety and Dust, pp. 27-30, 2000.

[4] M. L. Qvecoglu, B. Kuban, and H. Özer, "Characterization and crystallization kinetics of a diopside-based glass-ceramic developed from glass industry raw materials," Journal of the European Ceramic Society, vol. 17, no. 7, pp. 957-962, 1997.

[5] T. Kehagias, P. Komninou, P. Kavouras, K. Chrissafis, G. Nouet, and T. Karakostas, "Crystal phase separation and microstructure of a thermally treated vitrified solid waste," Journal of the European Ceramic Society, vol. 26, no. 7, pp. 1141-1148, 2006.

[6] Z. J. Wang, W. Ni, Y. Jia, L. P. Zhu, and X. Y. Huang, "Crystallization behavior of glass ceramics prepared from the mixture of nickel slag, blast furnace slag and quartz sand," Journal of Non-Crystalline Solids, vol. 356, no. 31-32, pp. 1554$1558,2010$.

[7] G. A. Khater, "The use of Saudi slag for the production of glass-ceramic materials," Ceramics International, vol. 28, no. 1, pp. 59-67, 2002.

[8] T. Toya, Y. Tamura, Y. Kameshima, and K. Okada, "Preparation and properties of $\mathrm{CaO}-\mathrm{MgO}-\mathrm{Al}_{2} \mathrm{O}_{3}-\mathrm{SiO}_{2}$ glass-ceramics from kaolin clay refining waste (Kira) and dolomite," Ceramics International, vol. 30, no. 6, pp. 983-989, 2004.

[9] H. Liu, H. Lu, D. Chen, H. Wang, H. Xu, and R. Zhang, "Preparation and properties of glass-ceramics derived from blast-furnace slag by a ceramic-sintering process," Ceramics International, vol. 35, no. 8, pp. 3181-3184, 2009.

[10] S. Banijamali, H. R. Rezaei, B. Eftekhari Yekta, and V. K. Marghussian, "Sinterability, crystallization and properties of glass-ceramic tiles belonging to $\mathrm{CaF}_{2}-\mathrm{CaO}-\mathrm{MgO}-\mathrm{Al}_{2} \mathrm{O}_{3}-\mathrm{SiO}_{2}$ system," Ceramics International, vol. 33, no. 8, pp. 1557-1561, 2007.

[11] K. Cai, "Comprehensive utilization of Baotou iron and steel company new blast furnace slag," Science \& Technology of Baotou Steel, vol. 34, pp. 77-80, 2008.

[12] W. Q. Peng and H. N. Xiao, "The impact of fluoride on CaO$\mathrm{Al}_{2} \mathrm{O}_{3}-\mathrm{SiO}_{2}$ system glass crystallization behavior," Materials Development and Application, vol. 16, pp. 16-17, 2001.

[13] B. Yu, K. Liang, A. Hu, and S. Gu, "Influence of different $\mathrm{TiO}_{2}$ content on crystallization of $\mathrm{CaO}-\mathrm{MgO}-\mathrm{P}_{2} \mathrm{O}_{5}-\mathrm{SiO}_{2}$ system glasses," Materials Letters, vol. 56, no. 4, pp. 539-542, 2002. 
[14] W. Q. Peng, $\mathrm{CaO}-\mathrm{MgO}-\mathrm{Al}_{2} \mathrm{O}_{3}-\mathrm{SiO}_{2}$ system glass-ceramics [M.S. thesis], Hunan University, Hunan, China, 2000.

[15] H. N. Xiao, Y. Liu, and H. X. Shi, "Effects of content of blast slag and heat-treatment parameters on properties of slag glassceramics," Science and Art of Ceramic, pp. 42-46, 2003.

[16] E. Rowlands and P. F. James, "Analysis of steady state crystal nucleation rates in glasses," Physics and Chemistry of Glasses, vol. 20, pp. 2-14, 1979. 

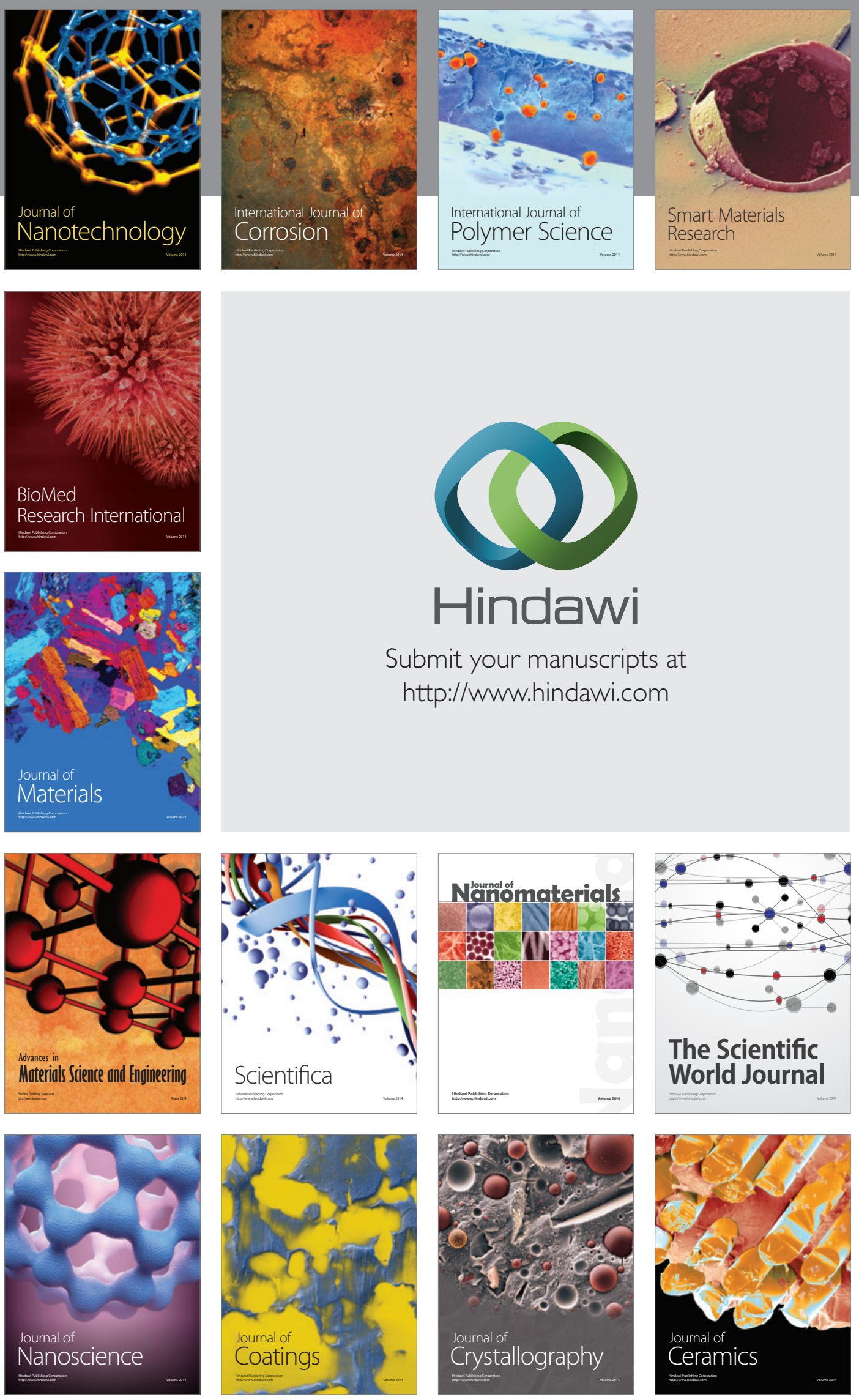

The Scientific World Journal

Submit your manuscripts at

http://www.hindawi.com

\section{World Journal}

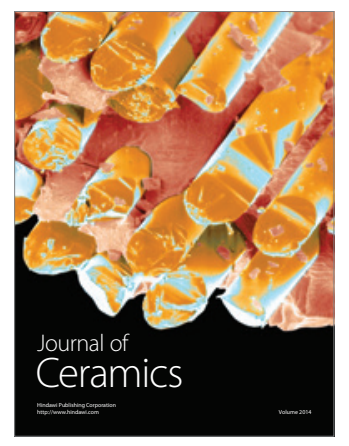

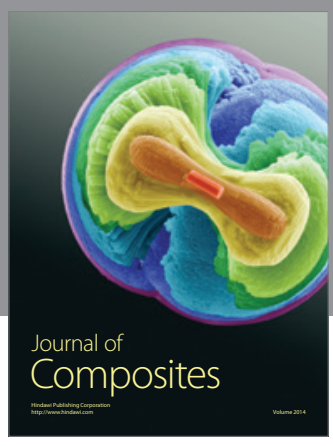
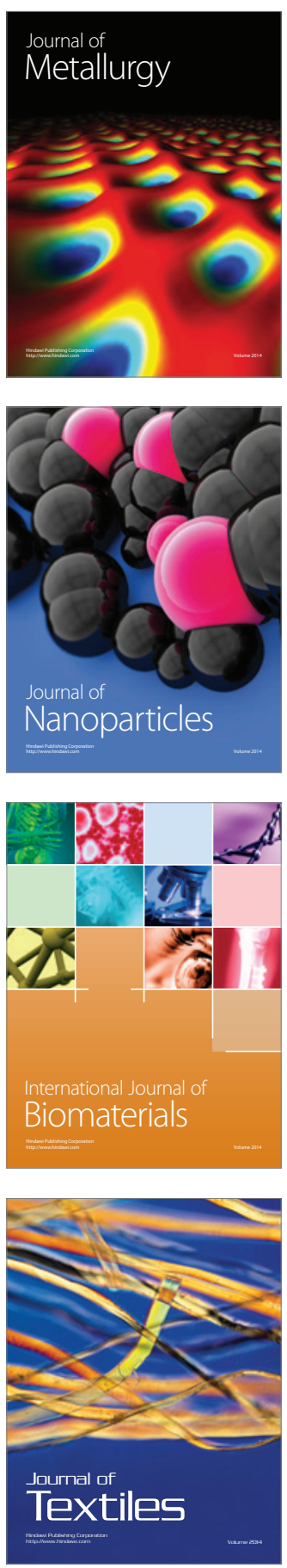